\begin{tabular}{|c|c|}
\hline \multirow{3}{*}{ 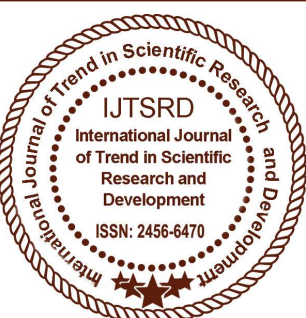 } & $\begin{array}{l}\text { International Journal of Trend in Scientific } \\
\text { Research and Development (IJTSRD) }\end{array}$ \\
\hline & International Open Access Journal \\
\hline & ISSN No: 2456 - 6470 | www.ijtsrd.com | Volume - 2 | Issue - 5 \\
\hline
\end{tabular}

\title{
Removal of Fluoride Using Brick Chip by Adsorption Prepared from Laterite Soil Area of Bihar \& Jharkhand
}

\author{
Sunita Singh ${ }^{1}$, Dr. Sushil Kumar Singh ${ }^{2}$ \\ ${ }^{1}$ Research Scholar, P. G Department of Environmental Science, Magadh University, Bodh Gaya, Bihar, India \\ ${ }^{2}$ Research Guide, Department of Botany, A. N College, Patna, Bihar, India
}

\begin{abstract}
The ability of lateritic soils to remove fluoride from water has been studied. Important issues considered in the study include the relation between the mineral composition of soils and their ability to remove fluoride, The effect of thermal treatment of the soil on fluoride removal; the predominant fluoride containing species remain in the treated water and the possible mechanism of fluoride removal by lateritic soils.
\end{abstract}

Fluoride contamination in drinking water due to natural and anthropogenic activities has been recognized as one of the major problems worldwide imposing a serious threat to human health. Presence of fluoride in low concentration $(<1.5 \mathrm{mg} / \mathrm{l})$ is beneficial to the people for the calcification of dental enamel and maintenance of healthy bones. On the other side, its presence in higher concentration become a monster and can cause dental, skeletal fluorosis and also non-skeletal problems. Among several treatment technologies applied for fluoride removal, adsorption process has been explored widely and offers satisfactory results especially with mineralbased and/or surface modified adsorbents. It is evident from the literature survey that various adsorbents have shown good potential for the removal of fluoride. However, still there is a need to find out the practical utility of such developed adsorbents on a commercial scale, leading to the improvement of pollution control. Many investigators conducted experiments and developed various low-cost technologies to remove fluoride from water and wastewater. However, selection of appropriate treatment method depends on local situation. In this experiment fluorine removal from water by adsorption is studied. Optimum conditions of the experiment have been expressed.
Environmental aspects of the adsorbent have been analysed.

Keywords: Fluoride removal, Late rite soils, Speciation analysis, Adsorption capacity, Thermal treatment

\section{INTRODUCTION}

Fluoride ion exists in natural waters and it is an essential micronutrient in humans in preventing dental caries and in facilitating the mineralization of hard tissues, if taken at a recommended range of concentration. Higher level of fluoride in groundwater is a world-wide problem, which includes various countries from Africa, Asia And USA. Bihar \& Jharkhand is among the most affected in India by the fluoride problem. Fluoride concentration, as high as $35 \mathrm{mg} / \mathrm{L}$, has been reported in drinking water sources in Gaya (Bihar). Excess fluoride in drinking water is prevalent in all of the Jharkhand regions of our country.

The term late rite is used as a common name for iron oxide rich tropical soils, which have been formed under weathering of rocks under strongly oxidizing and leaching conditions that leads to the removal of silica, alkalis and alkaline earths. This process, referred to as Late risation, leads to an accumulation of sparingly soluble compounds as the more soluble constituents of the parent rocks are leached out. The mineral compositions of lateritic soils vary greatly depending on the stage of laterisation. Lateritic soils, even when silica poor, may contain clay minerals, iron oxide minerals (goethite, hematite) and hydrated oxide of aluminum (gibbsite). In the final stage of laterisation, bauxite is formed. Laterites differ from 
clay soils in that aluminum is present as oxides or hydroxides instead of silicates.

Water is one of an essential commodity for the survival of all forms of lives on the earth. The population explosion and rapid industrial growth demands huge quantity of fresh water to meet various requirements. Of the total quantity of water $(1.38 \times 109 \mathrm{~km} 3)$ available on the earth, $3 \%$ only is the fresh water. Of this $3 \%$ of fresh water, $1.74 \%$ is in glacier form, $1.7 \%$ as ground water and the rest in the other forms. Very small quantity of water $(0.0131 \%$ of total water) only is available in the rivers and lakes and most of these water sources are getting polluted due to waste disposal and human activities. India is one among the 23 nations in the world, where the fluoride contaminated groundwater is creating the health problems. Fluorosis was first detected in early 1930s in four states of India. In 1986, 13 states and in 1992, two more states were added to this list. It has been reported as many as 177 districts in 19 states and Union Territories of India have already been affected by fluorosis. Most of the rural population depends on the ground water sources for drinking purposes which generally contain underground deposits such as salts and minerals. One such is the fluoride which causes an adverse impact on human as well as animal health if fluoride concentration is higher. Consumption of water having excess fluoride over a prolonged period leads to a chronic ailment known as fluorosis. According tothe recent study, 62 million people are affected by various degrees of fluorosis in India alone. Out of these; 6 million are affected with a dental, skeletal and non-skeletal form of fluorosis and associated health problems. Fluorine is often called as two-edged sword. The positive side is about $96 \%$ of fluoride in the human body is found in bones and teeth. Fluorine is essential for the normal mineralisation of bones and formation of dental enamel. On the negative side, prolonged ingestion of fluoride through drinking water in excess of the daily requirement is associated with dental and skeletal fluorosis. Standards prescribed by various regulatory bodies for fluoride concentration in drinking water are different according to their climatic conditions. According to the World Health Organization (WHO), the standard prescribed for fluoride ion concentration in drinking water is $1.0 \mathrm{mg} / \mathrm{l}$ whereas by Bureau of Indian Standards (BIS) it is $1.0 \mathrm{mg} / \mathrm{l}$. Fluoride in smaller dose $(0.8-1.0 \mathrm{mg} / \mathrm{l})$ helps to prevent dental caries particularly in the children below 8 years of age. Fluoride in higher concentration causes dental fluorosis $\left(\begin{array}{ll}1.5 & -2.0 \mathrm{mg} / 1)\end{array}\right)$ and skeletal fluorosis $(>3.0 \mathrm{mg} / \mathrm{l})$.

Although the adsorption capacity of the soils is low, their availability in large amounts and low costs make them potential candidates for the defluoridation in remote rural areas. It is important to compare the defluoridation ability of the soils with their chemical and mineralogical composition and also to understand the possible mechanisms of fluoride adsorption. The research works done so far have concentrated on the fluoride "removal capacity" of the soils based on total fluoride removed with no to conduct speciation analysis of the free fluoride and complexed fluoride. Thus, the purpose of this study was to determine the adsorption capacity of thermally treated lateritic soil and to analyze both free and complexed fluoride in the treated water.
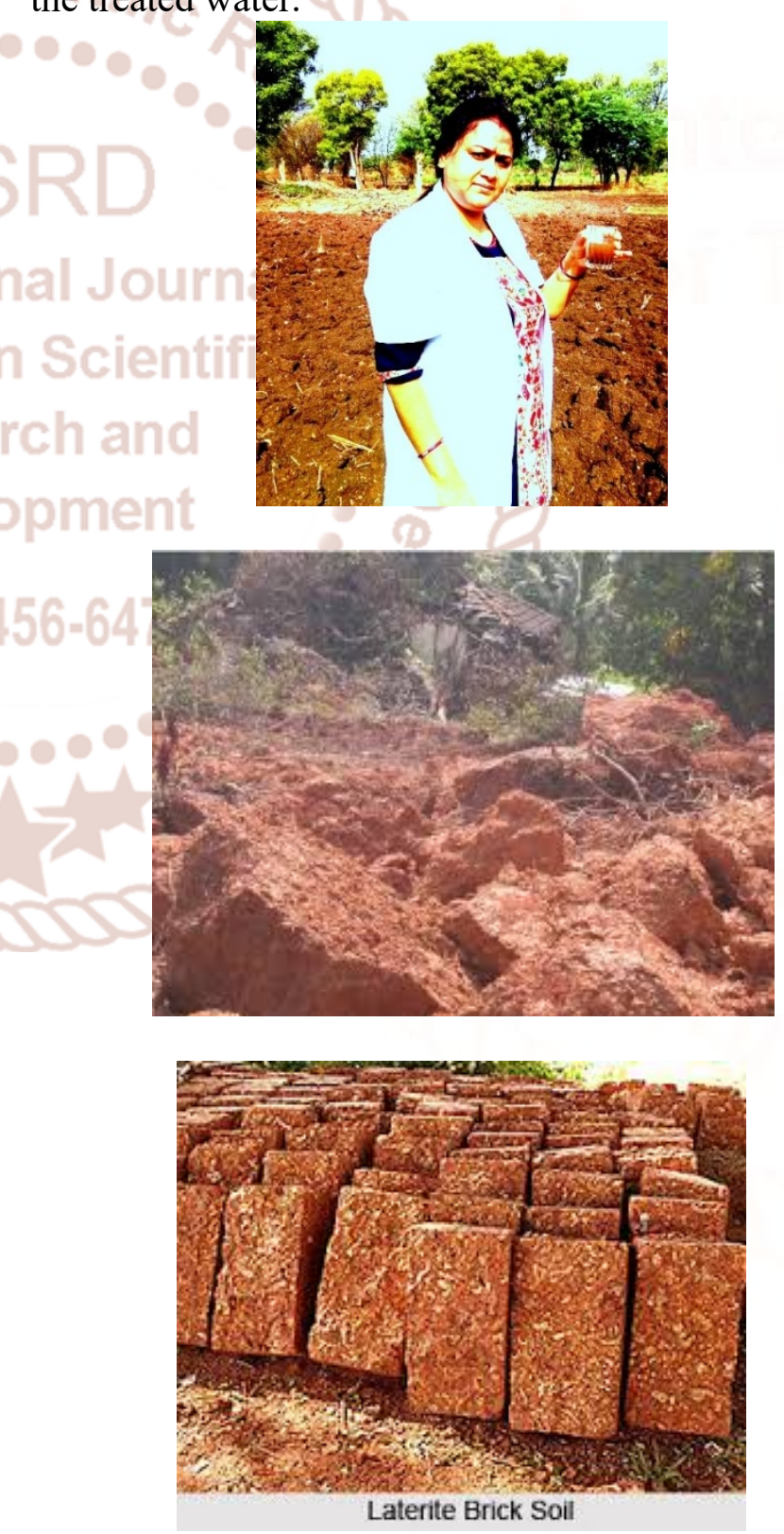


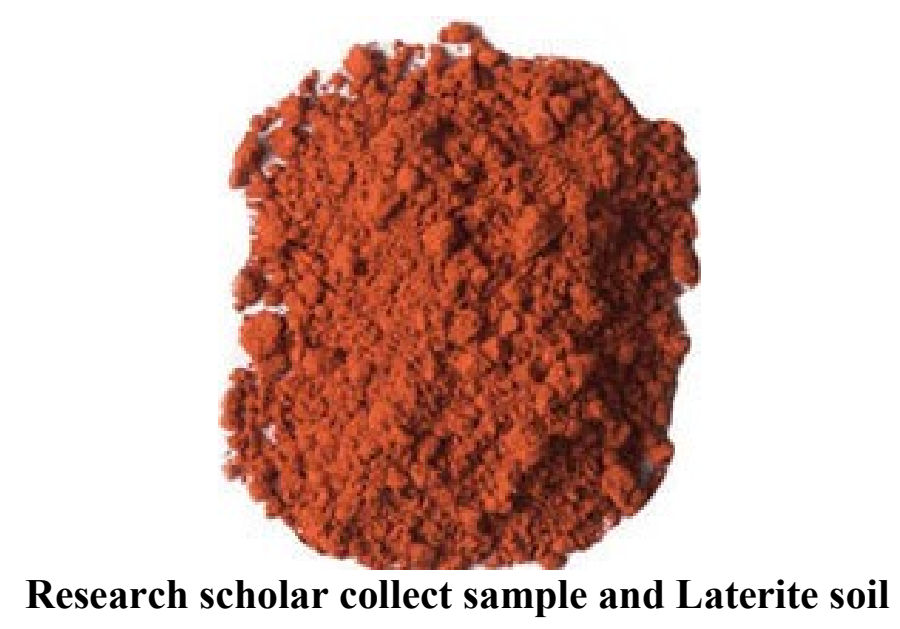

\section{SOURCES OF FLUORIDE}

The amount of fluoride stored across the world in the ground is estimated to 85 million tons and nearly 12 million tons are located in India. The principal sources of fluorine were drinking water and food such as sea fish, cheese and tea. Fluoride is present in all waters particularly in ground water with higher concentrations. There has been an escalation in daily fluoride intake via the total human food and beverage chain. Carbonated soft drinks have considerable amounts of fluorides. Beers brewed in locations with high fluoride water levels may contribute significantly to the daily fluoride intake and sweetened iced teas contain significant amounts of fluoride. A single serving of chicken sticks alone would provide about half of a child's upper limit of safety for fluoride. Children's ingestion of fluoride from juices and juiceflavoured drinks can be substantial and a factor in the development of fluorosis. Fluoride is also present in most of everyday needs, viz. toothpastes, drugs, cosmetics, chewing gums, mouthwashes, and so on. The most common fluorine-bearing minerals, which constitute natural source for fluoride in drinking water are fluorite $(\mathrm{CaF} 2)$, apatite $(\mathrm{Ca} 10$ (PO4)6F2), rock phosphate and topaz (A12 (F, OH)2SiO4). Artificially high soil $\mathrm{F}$ levels can occur through contamination by application of phosphate fertilizers or sewage sludges, or from pesticides. Rocks in southern India are rich with fluoride which forms the major reason for fluoride contamination in groundwater, and the granites in the district of Nalgonda, Andhra Pradesh contain much higher fluoride than the world average fluoride concentration of $808 \mathrm{mg} / \mathrm{kg}$. Fluoride contamination in ground water is a world-wide issue. The information regarding occurrence of fluoride in ground water in India.

\section{METHODS FOR FLUORIDE REMOVAL}

Treatment of water and wastewater containing fluoride ions requires a suitable and effective method. Membrane filtration, precipitation, nanofiltration, ionexchange, electro coagulation, flotation, reverse osmosis and adsorption have been used for fluoride removal. Most of these methods have high operational and maintenance cost, low fluoride removal capacities, lack of selectivity for fluoride, undesirable effects on water quality, generation of large volumes of sludge and complicated procedures involved in the treatment. Among these methods, adsorption is the most effective and widely used method because it is universal, has a low maintenance cost, and is applicable for the removal of fluoride even at low concentrations. In recent years, considerable attention has been focused on the study of fluoride removal using natural, synthetic and biomass materials such as activated alumina, fly ash, alum sludge, chitosan beads, red mud, zeolite, calcite, hydrated cement, attapulgite, and acid-treated spent bleaching earth. Reverse osmosis is an excellent choice for the reduction of fluoride. Using a cellulose acetate/cellulose triacetate (CA/CTA) membrane, rejection rates of $80-90$ percent are achievable when the $\mathrm{pH}$ is in the 4-8.5 range. Thin Film Composite membranes (TFC) will yield a higher rejection rate (up to 95 percent) in the $3-11 \mathrm{pH}$ range. Both the CA/CTA and TFC membranes should be operated at a minimum membrane pressure differential of at least 30 psi. Defluoridation methods can be broadly divided into three categories according to the main removal mechanism:

$>$ Chemical additive methods

$>$ Contact precipitation

$>$ Adsorption/ion exchange methods.

\section{CHEMICAL ADDITIVE METHODS}

These methods involve the addition of soluble chemicals to the water. Fluoride is removed either by precipitation, co precipitation, or adsorption onto the formed precipitate. Chemicals include lime used alone or with magnesium or aluminum salts along with coagulant aids. Treatment with lime and magnesium makes the water unsuitable for drinking because of the high $\mathrm{pH}$ after treatment. The use of alum and a small amount of lime has been extensively studied for defluoridation of drinking water. The most popular method for removal of fluoride from water is the Nalgonda technique, involves adding lime (5\% of 
alum), bleaching powder (optional) and alum (A12 (SO4)3.18H2O) in sequence to the water, followed by coagulation, sedimentation and filtration. A much larger dose of alum is required for fluoride removal (150 $\mathrm{mg} / \mathrm{mg} \mathrm{F-),} \mathrm{compared} \mathrm{with} \mathrm{the} \mathrm{doses} \mathrm{used} \mathrm{in}$ routine water treatment. Nalgonda technique is carried out with easily available chemicals and the method is economically attractive. The limitations of the method are varying alum doses depending on fluoride levels in water, daily addition of chemicals and stirring for 10-15 min, which many users may find difficult.

\section{CONTACT PRECIPITATION}

Contact precipitation is a recently reported technique in which fluoride is removed from water through the addition of calcium and phosphate compounds. The presence of a saturated bone charcoal medium acts as a catalyst for the precipitation of fluoride either as $\mathrm{CaF} 2$, and/or fluorapatite. It gives high efficiency.

\section{ION-EXCHANGE METHOD}

In the adsorption method, raw water is passed through a bed containing defluoridating material. The material retains fluoride either by physical, chemical or ion exchange mechanisms. The adsorbent gets saturated after a period of operation and requires regeneration. A wide range of materials has been carried out for fluoride uptake such as Bauxite, magnetite, kaolinite, serpentine, various types of clays and red mud are some of the naturally occurring materials were studied. The general mechanism of fluoride uptake by these materials is the exchange of metal lattice hydroxyl or other anionic groups with fluoride. Fluoride uptake capacity can be increased by certain pre-treatment like acid washing, calcinations, etc.

\section{EXPERIMENTAL METHODOLOGY}

Materials: Corning glassware of 'Pyrex' quality and analytical reagent grade chemicals were used. The glassware was soaked overnight in a $5.0 \mathrm{mg} / \mathrm{L}$ of Fluoride solution to minimize the possibility of Fluoride getting absorbed. The glassware was washed off with nitric acid and distilled water before use. First, a stock solution of $100 \mathrm{mg}$ F/L was prepared by dissolving appropriate amount of sodium fluoride $(\mathrm{NaF})$ in distilled water and desired concentrations of working solutions were then prepared from stock solution. Sulphuric acid $(0.1 \mathrm{~N})$ and sodium hydroxide $(0.1 \mathrm{~N})$ were used for adjusting the $\mathrm{pH}$ values either to acidic or alkaline conditions.
Aundantly available low cost materials like brick powder were utilized Brick powder was sieved through IS sieves of $150 \mu \mathrm{m}$ and $300 \mu \mathrm{m}$ size and the material passing through $150 \mu \mathrm{m}$ and retained on 300 $\mu \mathrm{m}$ which has a geometric mean size $(\mathrm{Gm})$ of $212 \mu \mathrm{m}$ was used in all experiments.

Non-flow batch sorption studies were conducted to study the effect of controlling parameters like contact time, sorbent dosage, solution $\mathrm{pH}$ etc. Continuous down flow column studies were also conducted to study the practical applicability of brick powder for removal of Fluorides from water. All the experiments were conducted at room temperature (29 $\pm 20 \mathrm{C}$ ). Fluoride concentration was estimated by SPADNS method (APHA) using a SYSTRONICS-105 spectrophotometer.

\section{RESULTS AND DISCUSSION}

\section{Removal of Fluoride by brick powder}

The effect of contact time on removal on Fluoride using brick powder is presented graphically as Fluoride removal in ppm at different contact timesIt may be observed increases, ppm removal also increases initially and reduces gradually with time and attains almost an equilibrium condition in nearly 72 hours and remains more or less constant thereafter. A maximum of 85 percent removal could be accomplished by brick powder.

\section{Effect of Solution pH}

Removal of Fluoride by brick powder decreased continuously as $\mathrm{pH}$ was increased from 2.5 to 11.0. Decrease in removal of Fluoride in $\mathrm{pH}$ range of 2.5 to 10.7 was low i.e., $12.5 \%$ whereas removal of Fluoride deceased significantly from $\mathrm{pH} 10.0$ to 12.0 . Marginal variation in Fluoride removal by brick powder over $\mathrm{pH}$ range of 2 to 10 indicates its usefulness for removal of Fluoride in the $\mathrm{pH}$ range normally encountered in ground waters laden with Fluoride.

\section{Effect of Sorbent Dose}

Results of equilibrium sorption experiments conducted with a test Fluoride solution of concentrations $10 \mathrm{mg} / 1$. The amount of Fluoride adsorbed increased with increase in dose and $84 \%$ removal was accomplished at a dosage of $9 \mathrm{~g} / \mathrm{l}$. At higher doses than $9 \mathrm{~g} / \mathrm{l}$ there is no increase in Fluoride removal perhaps due to non absorbability of Fluoride ions. 


\section{CONCLUSION}

The experimental investigations clearly suggest that abundantly available and low-cost materials like brick powder, is effective in removing Fluoride from water to acceptable levels. Equilibrium isothermal sorption experiments suggested that sorbent dosages of $9 \mathrm{~g} / 1$ of brick powder accomplished a removal of $85 \%$ of Fluoride. The time to reach equilibrium was observed to be 72 hours. $\mathrm{pH}$ does not have any significant impact in the range of 2-10, whereas $\mathrm{pH}$ of more than 10 resulted in a steep decrease in Fluoride removal.

\section{REFERENCE}

1. MARUTHAMUTHU and SIVASAMY (1994) Defluoridation by zeolites and aphophyllites. Fluorides 27(2) 81-88.

2. MUNOZ JL and LUDINGTON SD (1974) Fluoride-hydroxyl exchange in biotite. Am. J. Sci. 274396-413.

3. ROMO LA (1954) Role of lattice hydroxyls in phosphate fixation and their replacement of fluoride. J. Colloid. Chem. 9385-392.

4. ROMO LA and ROY R (1957) Studies of the substitution of $\mathrm{OH}-$ by $\mathrm{F}$ in various hydroxylic minerals. Am. Miner. 42165-177.
5. SAMSON HR (1952) Fluoride adsorption by clay minerals and hydrated aluminium. Clay Minerals $1266-271$.

6. SRINIVASAMORTHY K (1996) Unpublished M.Sc. dissertation. Annamali Univ., India. 87 pp.

7. STORMER JC and CARMICHAEL ISE (1971) Fluoride hydroxyl exchange in Apatite and Biotite. A potential geothermometer. Contrib. Miner. Petrol 31167-189.

8. ZHANG QIANILE (1992) Aluminophosphate for the defluoridation of potable water. Environ. Int. 18307-310.

9. Singh K., Hundal, H. S. and Singh, D. (2011): Geochemistry and assessment of hydro geochemical processes in groundwater in the southern part of Bathinda district of Punjab, northwest India Environ Earth Sci., 64:18231833. DOI: $10.1007 / \mathrm{s} 12665-011-0989-9$.

10. Srinivasa Rao, K.V., Subba Rao, N., Murali Krishna, B., Subrahmanyam, A., John Devadas, D. and Thirupathi Rao, B. (2007): Temporal Changes in Groundwater Quality in an Industrial Area of Andhra Pradesh, India. Current Sci., 93: 1616-1619. 